\title{
O IMPULSO DO CRÉDITO RURAL NO PRODUTO DO SETOR PRIMÁRIO BRASILEIRO
}

Marcelo Miranda Melo ${ }^{1}$

Émerson Lemos Marinho ${ }^{2}$

Almir Bittencourt Silva ${ }^{3}$

RESUMO: Este artigo analisa o impacto do crédito rural no Produto Interno Bruto (PIB) agropecuário da economia brasileira no período 1995 a 2009. Os resultados dos modelos econométricos demonstraram a causalidade bidirecional entre o crédito rural como proporção do PIB real agropecuário e esse último. Analisam-se, também, as modalidades de crédito rural destinadas ao investimento, custeio e comercialização da produção rural, além das séries de crédito rural para à agricultura e pecuária. O crédito rural para a comercialização e à agricultura em relação ao PIB real do setor agropecuário impactou positivamente esse último. Um choque positivo de $4,23 \%$ no crédito para a comercialização em relação ao PIB real desse setor tende a impactar o PIB real agropecuário em 1,89\%. Já um choque de 1,90\% no crédito destinado à agricultura em relação ao PIB real impacta o PIB real agropecuário em 0,79\%.

Palavras-chave: Crédito rural. Crescimento econômico. VAR e causalidade.

\footnotetext{
${ }^{1}$ Doutor em Economia, professor adjunto da Universidade Federal do Ceará (UFC), marcelomelo@ ufc.br

${ }^{2}$ Doutor em Economia, professor titular Universidade Federal do Ceará (UFC), emarinho@ufc.br

${ }^{3}$ Doutor em Economia, Secretário adjunto de Ciência e Tecnologia do Estado do Ceará, almir_eco@ ufc.br
} 
ABSTRACT: This article analyses the farming credit impact in the Brazilian real farming GDP between 1st quarter 1995 until 1st quarter 2009. The results from the econometric models showed bi-directional causality between total farming credit in relation to real farming GDP and the real GDP of the farming sector. This study also investigated the following types of rural credit availability: rural credit for investment, rural credit for costing, rural credit for marketing, rural credit for agriculture and rural credit for cattle-raising. The rural credit series for marketing and for agriculture in relation to real farming GDP showed positive impact in the real GDP of the farming sector. A credit shock of $+4,23 \%$ in the rural credit for marketing availability in relation to the real farming GDP tends to impact the real GDP of the rural sector in $+1,89 \%$. On the other hand, a credit shock of $+1,90 \%$ in the rural credit for agriculture in relation to the real farming GDP tends to impact the real GDP of the farming sector in $+0,79 \%$.

Keywords: Credit for agriculture. Economic growth. VAR and causality.

\section{INTRODUÇÃO}

O Brasil é um dos líderes mundiais na produção e exportação de vários produtos agropecuários. O país apresenta vantagens comparativas importantes que tendem a fomentar a participação crescente do Brasil na produção agropecuária mundial.

O complexo agroindustrial brasileiro desempenha um papel relevante na economia nacional. Estima-se que 30\% do Produto Interno Bruto (PIB) estejam ligados a produtos e serviços relacionados ao agronegócio. (NUNES; CONTINI, 2001)

O PIB agrícola registrou entre 1986 e 2004 uma taxa de crescimento de $3,6 \%$ ao ano enquanto que a economia como um todo se limitou a $2,1 \%$ ao ano nesse período. Como se observa, esse setor em comparação com o PIB total apresenta um potencial de crescimento a despeito das dificuldades que o setor tem enfrentado.

A produção agropecuária tende a apresentar impacto relevante sobre os índices de preços no Brasil. Variações significativas na produção pecuária e nas safras agrícolas apresentam influência relevante nos índices de preços no médio e longo prazo.

Outro aspecto igualmente relevante é o impacto social que o crédito ao setor primário sugere ter. Na medida em que o crédito rural é incrementado no setor agropecuário, sugere-se uma redução nos índices de pobreza no 
campo, menor fluxo migratório para as grandes cidades e redução dos bolsões de pobreza nas grandes metrópoles brasileiras, aliviando também os elevados índices de violência com a fixação desta mão de obra no campo.

Por exemplo, no Paquistão, ${ }^{4}$ segundo Akram e outros (2008) a elasticidade do crédito direcionado para agricultura em relação à pobreza foi de $-0,35$ no curto prazo e -0,27 no longo prazo.

O acesso ao crédito deve elevar a eficiência técnica bem como a alocação eficiente no setor agrícola. Este acesso ao crédito rural permite aos produtores rurais adotarem métodos de produção, capital-intensivo, como compra de mais máquinas e implementos agrícolas. Mais ainda, o acesso ao crédito está correlacionado com a provisão de assistência técnica pelas instituições de crédito conforme apontam Chaovanapoonphol, Battese e Chang (2005).

O crescimento do setor rural é também um importante indutor para a economia como um todo. Variações na renda rural causam variações na demanda por produtos da indústria bem como do setor de serviços. Um estudo sobre demanda setorial na Índia de Chakrabarty (2003) concluiu que o aumento de uma unidade de produto na agricultura é provável que cause um aumento na demanda por produtos industriais de 0,297 unidades e de 0,149 unidades de produto no setor de serviços. Esse mesmo autor detectou também causalidade reversa entre o crédito e o crescimento do setor rural na Índia. Entretanto, o mercado é encorajado a alocar maiores serviços financeiros para o setor rural no sentido de incrementar uma maior produção agropecuária.

O crédito rural, segundo o Manual de Crédito Rural (MCR) do Banco Central (Bacen), é o suprimento de recursos financeiros que tem as seguintes finalidades:

a. Estimular os investimentos rurais, inclusive armazenamento, beneficiamento e industrialização de produtos agropecuários, quando efetuado pelo produtor na sua propriedade rural, por suas cooperativas ou por pessoas físicas ou jurídicas equiparadas aos produtores;

b. Favorecer o oportuno e adequado custeio da produção e a comercialização de produtos agropecuários;

\footnotetext{
${ }^{4}$ Observe que a elasticidade do crédito para a agricultura em relação à pobreza rural tem impacto maior no curto prazo. Contudo, mesmo no longo prazo ela é ainda significativa.
} 
c. Fortalecer o setor rural, notadamente no que se refere a pequenos e médios produtores;

d. Incentivar a introdução de métodos racionais no sistema de produção, visando ao aumento da produtividade, à melhoria do padrão de vida das populações rurais e à adequada defesa do solo.

O crédito rural sofreu grandes transformações ao longo das últimas décadas, influenciado por vários fatores, tais como: altos índices de inflação, variações nos preços dos insumos do setor, interferências políticas, restrição de recursos financeiros e outros. O financiamento do setor primário parece ser um ponto indutor relevante na produção deste tão importante setor da economia brasileira. Na seção seguinte é realizada uma análise mais detalhada destas mudanças no crédito rural e suas consequências.

Em função do que foi discutido anteriormente, o objetivo principal desse artigo é analisar e aferir o impacto das modalidades de crédito agropecuário de custeio, investimento e comercialização no PIB do setor primário brasileiro. Neste sentido, utilizam-se as técnicas econométricas de um modelo de Vetores Autoregressivos (VAR) e um teste de causalidade de Granger, empregando as variáveis PIB do setor primário, Sistema Especial de Liquidação e de Custódia (Selic), Índice Nacional de Preços ao Consumidor (INPC) e a série de crédito agrícola. O modelo VAR irá gerar as respectivas Função de Impulso Resposta (FIR) e a Decomposição de Variância de Cholesky (DVC).

No que se segue este artigo, além desta introdução, está organizado da seguinte maneira: a segunda seção apresenta um breve histórico da evolução do crédito rural no Brasil e o seu mecanismo de transmissão. Além do mais, discutem-se outros estudos feitos para o Brasil e outros países. Na terceira seção especificam-se os modelos econométricos propostos e suas variáveis. Na quarta seção são apresentados os resultados dos testes de estacionariedade, de causalidade de Granger, Função de Impulso Resposta e Decomposição de Variância de Cholesky. Por último, na quinta seção são apresentadas e discutidas as conclusões do artigo.

\section{BREVE HISTÓRICO DO CRÉDITO RURAL NO BRASIL}

O crédito ao setor primário sempre foi um ponto crucial para seu desenvolvimento. Segundo Conceição e outros (1998), existe uma significativa relação de causalidade entre o volume de recursos ao crédito rural e o produto da agricultura.

Mediante a relevância do tema e a necessidade de regulamentação da política de crédito rural, em 1965 foi criado o Sistema Nacional de Crédito 
Rural (SNCR) que teve como objetivos principais: financiar parte dos custos da produção agrícola, estimular a formação de capital, acelerar a adoção de novas tecnologias e fortalecer a posição econômica dos produtores, especialmente os pequenos e médios.

Em resumo, o SNCR tinha como finalidade fornecer créditos para investimento, custeio e comercialização da produção rural. Com a criação do SNCR, as fontes de recursos para financiamentos destinados à agricultura tiveram como origem o Orçamento da União e os depósitos à vista. Somente os depósitos à vista representaram cerca de $97 \%$ das aplicações.

Até o ano de 1985 o sistema de crédito rural trabalhou com juros reais negativos, o que atraiu uma grande demanda para fins especulativos e não voltados para atividade agropecuária. Levando em consideração o INPC, apenas a partir de 1992 a agropecuária começou a trabalhar com taxas de juros reais positivas. Considerando o Índice Geral de Preços - Disponibilidade Interna (IGP-DI) como deflator de juros nominais, constata-se que no período de 1985 a 1991, a agropecuária recebeu subsídios de R\$14,37 bilhões (agosto de 1994) correspondendo a 4,24\% do PIB agropecuário. No período de 1992 a 2003 os juros reais pagos nesse setor foram de R\$ 8,11 bilhões (agosto de 1994), correspondendo a 1,52\% do PIB do setor. (BACHA; DANELON; BEL FILHO, 2005)

A partir de 1986, com o fim da conta movimento, a introdução da correção monetária e a criação da poupança rural houve uma drástica redução na demanda por esse tipo de crédito. Após a estabilização dos preços em 1995, o crédito rural voltou a apresentar uma trajetória de crescimento, desta vez, porém, associada ao crescimento da produção agrícola. (MATOS, 2008)

Existe uma tendência do governo brasileiro de distanciar-se do financiamento direto ao setor primário e usar outros instrumentos para alavancar recursos para o sistema de crédito. Analisando-se a participação dos bancos públicos no crédito rural, em 2008 é verificada a parcela de 55\% no volume disponibilizado. No início do Plano Real, 1994-1995, esta participação era de $80 \%$. No sentido de aumentar a participação do setor privado no financiamento do agronegócio, foram criados instrumentos de financiamento da agricultura. Tais instrumentos foram instituídos pela Lei n. 11.076 de 30/12/2004, como por exemplo: o Certificado de Depósito Agropecuário (CDA), o Warrant Agropecuário (WA), o Certificado de Direitos Creditórios do Agronegócio (CDCA), a Letra de Crédito do Agronegócio (LCA) e o Certificado de Recebíveis do Agronegócio (CRA). (GASQUES; CONCEIÇÃO, 1999)

Os entraves para a formulação de uma política de crédito agrícola são inúmeros, o que compromete o desempenho desse setor tão relevante da 
economia brasileira. A partir do segundo semestre de 2007 foi constatada elevação nos preços das commodities ${ }^{5}$ agrícolas no cenário internacional, como a soja e o milho. Isso se deve ao aumento da demanda, com ênfase no crescimento populacional, da renda, da expectativa de vida, da concentração urbana, sobretudo nos países emergentes, com destaque para Brasil, China e Índia. (MATOS, 2008)

A redução no ritmo de empréstimos em meio à crise americana resultou em preocupações para os produtores rurais e cooperativas agropecuárias no Brasil. Como conseqüência, as tradings ${ }^{6}$, relevantes financiadoras da agricultura, limitaram as compras antecipadas, fato justificado pelas dificuldades de captação de recursos externos e pelas oscilações de preços das commodities.

A crise americana abalou não somente os países emergentes, mas, sobretudo, países do primeiro mundo com economias consolidadas e setor agropecuário bem definido em termos de financiamento. Todavia, segundo o Agriculture \& Rural Development Factsheet (2009) da Escócia relata:

A velocidade na qual a economia rural da Escócia irá se recuperar da recessão estará vinculado à restauração da confiança no setor financeiro, solucionar problemas de crédito rural, assegurar uma mão de obra qualificada e encorajar as empresas a investir no seu futuro. (ASSUNÇÃO; CHEIN, 2007)

Assunção e Chein (2007) em uma pesquisa sobre as condições de crédito no Brasil rural detectaram fortes indícios de racionamento de crédito e a concentração de recursos nas áreas mais desenvolvidas do país. Associados ao racionamento de crédito os produtores rurais enfrentam a seguinte situação: os provedores de crédito enfrentam uma série de dificuldades associadas ao contrato de crédito, pois não observam o tipo dos clientes, o que eles fazem com os recursos recebidos e se estão ou não dispostos a pagar o empréstimo. Estas situações de assimetria de informações ${ }^{7}$, risco moral e seleção adversa, tornam o racionamento de crédito mais exacerbado no setor primário da economia.

\footnotetext{
${ }^{5}$ Mercadorias que são cotadas em dólares no mercado internacional.

${ }^{6}$ Empresas que comercializam e financiam a produção agropecuária.

${ }^{7} \mathrm{O}$ mercado de crédito é um exemplo clássico de aplicação das assimetrias de informação, notadamente o risco moral e a seleção adversa. Especificamente, o mercado de crédito rural apresenta ainda mais especificidades devido a uma série de fatores: condições climáticas, subsídios para o setor, políticas sociais direcionadas ao setor rural etc.
} 
Motivados pelo racionamento de crédito rural os produtores rurais vêm promovendo uma mudança no financiamento da produção agrícola brasileira. Utilizando uma amostra com 2050 empresas agrícolas (pequenas, médias e grandes) pesquisadas na safra 98/99, apenas 33\% dos produtores fizeram uso do crédito rural oficial. Da referida amostra, $84 \%$ utilizaram recursos próprios, $13 \%$ troca por insumos, $10 \%$ teve como fonte de recursos as Cédulas de Produto Rural (CPR) e $8 \%$ tiveram créditos das empresas de insumos. (BELIK; PAULILLO, 2001)

Basicamente, as modalidades de crédito ao setor primário são: crédito para custeio da produção agrícola, crédito para investimento rural e crédito para a comercialização da produção rural. Apenas para investimento temos os seguintes programas: Programa de Incentivo à Irrigação e à Armazenagem (Moderinfra), Programa de Modernização da Agricultura e Conservação de Recursos Naturais (Moderagro), Programa de Plantio Comercial e Recuperação de Floresta (Propflora), Programa de Modernização da Frota de Tratores Agrícolas e Implementos Associados e Colheitadeiras (Moderfrota), dentre outros.

Diante dos riscos na atividade agropecuária decorrentes da aludida restrição de crédito e da expectativa da continuidade da elevação nos preços dos insumos, os produtores rurais devem reduzir os investimentos nas lavouras, o que certamente irá comprometer a produtividade agrícola. Contudo, segundo Sant'Anna e Ferreira (2006), o crédito rural cresceu a partir de 1996, associado ao aumento da produção agrícola.

Diante dessa restrição de crédito ao setor primário, pelas diversas razões já discutidas acima, saber quais modalidades de crédito possuem a capacidade de contribuir de forma mais relevante para a formação do PIB agrícola é de grande valia na formação de políticas públicas para o crédito agrícola, dada ao racionamento de crédito na economia brasileira. Além disso, essa pesquisa contribui no sentido de identificar o sentido da causalidade entre as principais variáveis macroeconômicas que afetam de forma direta e indireta a produção do setor primário brasileiro.

\section{MECANISMO DE TRANSMISSÃO DO CRÉDITO RURAL AO PIB DO SETOR PRIMÁRIO}

Na Figura 1, pode-se visualizar que os bancos (públicos e privados) e demais instituições de crédito, como cooperativas, tradings etc., disponibilizam limites de crédito aos produtores rurais mediante uma série de pré-requisitos estabelecidos na análise de crédito.

Em seguida, este crédito é concedido aos produtores rurais, destinado a três finalidades básicas: custeio da produção, investimento e 
comercialização. O crédito de custeio visa complementar as despesas com plantio, tratamento do solo, aquisição de insumos pecuários, ou seja, destina-se a cobrir despesas normais dos ciclos produtivos.

O crédito para investimento é destinado à ampliação de instalações de produção, aquisição de plantéis pecuários, máquinas e implementos agrícolas, dentre outros cujo desfrute se estende por vários períodos de produção. Esta linha visa induzir uma maior produtividade na produção rural gerando consideráveis ganhos de escala.

O crédito para comercialização é uma linha de financiamento que visa incrementar o processo de comercialização da produção agropecuária. Os preços das commodities agropecuárias em geral sofrem grandes oscilações, especialmente em períodos de instabilidade econômica internacional. Portanto, esta linha de crédito é adotada como medida anticíclica no sentido de estabilizar a comercialização da produção rural, minimizando os efeitos adversos da instabilidade internacional para os produtores rurais brasileiros.

Figura 1 - Mecanismo de transmissão do crédito rural ao crescimento econômico agropecuário

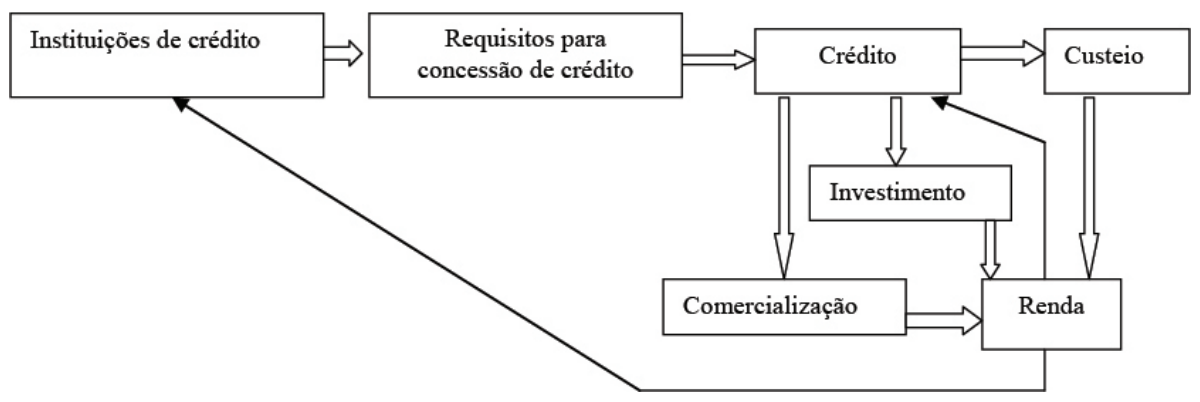

Fonte: Elaborado pelos autores.

Estas linhas de crédito rural geram renda que possuem um mecanismo de feedback com as instituições de crédito e outro com os limites de crédito disponíveis. Portanto, uma maior renda oriunda dos empréstimos ao setor rural irá incrementar de forma positiva os balanços das instituições de crédito. Com resultados positivos ${ }^{8}$, as instituições de crédito tendem a relaxar os requisitos para a concessão de crédito. Relaxando estes requisitos, as instituições irão oferecer maiores limites de crédito aos pretensos

\footnotetext{
${ }^{8}$ Considerando um choque monetário, os bancos tendem a ser bem mais cautelosos na concessão de crédito. O que irá se refletir num aperto dos requisitos de crédito ocasionando um menor volume de empréstimos e uma menor receita financeira para os bancos.
} 
tomadores de empréstimo. O crédito por sua vez será direcionado para custeio, investimento e comercialização da produção rural. Estes empréstimos irão gerar mais renda, que, por sua vez, irá beneficiar novamente os resultados contábeis das instituições de crédito e também induzir um maior volume de recursos para o crédito rural, retroalimentando o mecanismo de transmissão do crédito rural para o PIB do setor primário brasileiro.

O crédito rural corrente é influenciado pelo volume de crédito rural já concedido aplicado à agropecuária em períodos passados anteriores. Parece existir um mecanismo de feedback no fomento ao crédito. O PIB agropecuário também sugere influência no volume de crédito rural. Um incremento no PIB agropecuário deve induzir um maior volume de crédito rural no sentido de manter este novo nível de produção e vice-versa. A taxa de juros também apresenta influência no crédito rural. Taxa de juros reais mais elevadas devem inibir a contratação de empréstimos para o setor rural. O nível de preços é influenciado pelo volume de crédito rural. O crédito rural incrementa a produção agropecuária que oferta um maior volume de produtos ao mercado reduzindo os níveis de preços.

O PIB agropecuário corrente é também influenciado pelo PIB agropecuário de períodos passados, pois se espera que as políticas públicas para o setor não sofram mudanças bruscas. O crédito rural deve interferir na produção agropecuária no sentido de fomentar um maior valor de produção do setor rural à medida que maiores valores de crédito rural sejam injetados. O PIB agropecuário é também influenciado pela taxa de juros. Taxas de juros reais elevadas afetam o produto agropecuário brasileiro inibindo a atividade do setor. O nível de preços deve interferir no PIB agropecuário de forma indireta. Com um maior nível de preços na economia, o Bacen deverá elevar as taxas de juros e consequentemente elevar também as taxas de juros dos empréstimos agropecuários, inibindo a produção rural.

\section{PESQUISAS E EXPERIÊNCIAS COM CRÉDITO RURAL}

Um projeto de crédito rural foi desenvolvido no Vietnã, financiado pelo Banco de Desenvolvimento da Ásia (1996-1997) no valor de 50 milhões de dólares. O referido projeto tinha como principais objetivos promover o crescimento econômico, diversificar a economia rural, reduzir a pobreza rural, aumentar a renda familiar, expandir o emprego rural e fortalecer o sistema financeiro rural através da provisão de fundos de longo prazo. (ASIAN DEVELOPMENT BANK, 2005) O PIB aumentou a uma taxa anual de $6,2 \%$ durante a vigência do projeto. No setor da agricultura, o PIB correspondente aumentou a uma taxa anual de 5,2\% durante a vigência 
do projeto. A pobreza rural foi reduzida drasticamente de $66,4 \%$ (1993) para $35,6 \%$ (2002).

Uma pesquisa foi desenvolvida no sentido de identificar o impacto da demanda final do setor agropecuário sobre a produção, renda e importações do Paraná nos anos de 1980, 1985, 1990 e 1995, a partir das matrizes de insumo-produto. (FRANCO et al., 2005) Os resultados evidenciaram que a agropecuária é um setor-chave da economia paranaense, sendo o maior fornecedor de insumos para os outros setores. Esta pesquisa sugere que incrementando o PIB agropecuário existirão reflexos na produção de outros setores da economia regional.

Já Akram e colaboradores (2008), medindo o impacto do crédito à agricultura no crescimento econômico e pobreza no Paquistão, detectaram que o crédito direcionado para agricultura tinha uma elasticidade de curto prazo em relação ao PIB de 0,031 menor do que no longo prazo, que foi de 0,162 . Por sua vez, o crédito direcionado para agricultura como proporção do PIB da agricultura apresentou uma elasticidade de 0,13. Em países essencialmente agrícolas esta relação tende a ser muito significativa.

O crédito é um instrumento importante para agricultura por possibilitar o investimento em capital fixo e capital humano, insumos básicos da atividade, facilitando o processo de produção e inovação. $O$ crédito também permite que o agricultor possa regular o fluxo de seu consumo pessoal e de insumos para a produção, compatibilizando-o com o fluxo de sua renda, que pode ser contínuo ou sazonal. Conclusões tiradas de Pereira, Figueiredo e Loureiro (2006).

Bonelli (2001) em pesquisa do Instituto de Pesquisa Econômica Aplicada (Ipea) conclui que a renda da agropecuária está estreitamente relacionada à dos demais setores econômicos, ao crescimento populacional e às melhorias nas condições de vida; a renda da agropecuária causa a renda urbana; tanto a renda da agropecuária como a dos outros setores têm influência importante sobre as receitas correntes dos municípios e há forte associação entre o nível de renda da agropecuária e o Índice de Condições de Vida (ICV) dos anos analisados.

Castro e Teixeira (2004) desenvolveram pesquisa sobre o retorno dos gastos com a equalização das taxas de juros do crédito rural na economia brasileira. A equalização das taxas de juros (ETJ) equivale à diferença entre as taxas de juros cobradas pelo mercado financeiro e as taxas de juros 
pagas pelo produtor rural. O valor disponibilizado pela ETJ corresponde a aproximadamente $30 \%$ do volume total de crédito aplicado na agricultura. Os resultados demonstram que, para cada real gasto com a equalização ${ }^{9}$, gera-se um crescimento no PIB equivalente a 3,57 vezes o gasto com a ETJ para a agricultura comercial, além de aumento na arrecadação de tributos de $37 \%$ do gasto com a ETJ para a agricultura comercial. Portanto, os benefícios são bem maiores que os gastos na ETJ para a produção rural.

Xavier e colaboradores (2008) analisaram as causas da inadimplência ao crédito rural e, dentre as conclusões, destacamos: ter experiência de crédito com outras instituições financeiras e ter crédito adequado às necessidades ajudam a reduzir a inadimplência.

Gasques e Conceição (1999) verificaram os fatores condicionantes da produtividade da agropecuária brasileira. Utilizando um modelo VAR detectaram que um impacto maior na produtividade dos fatores ocorre no segundo ano após um choque na variável gasto com pesquisa e na variável crédito rural. Esses efeitos foram da ordem de 0,22\% e 0,11\%, respectivamente e desaparecem após o terceiro ano.

Figueiredo e Castro (2007) estudaram sobre a relação crédito rural do Programa Nacional de Fortalecimento da Agricultura Familiar (Pronaf) e valor bruto da produção nos diferentes estados brasileiros. Os resultados mostram que existem diferenças regionais na relação do crédito com o valor bruto da produção, a qual, de modo geral, é significativa e positiva. Conclui-se que a eficiência do programa depende das diferenças regionais, devendo-se melhorar a distribuição do crédito, com o objetivo de melhorar a eficiência produtiva nas regiões mais pobres.

Cavalcante (2008) pesquisou a causalidade entre crédito rural e produto agropecuário utilizando a metodologia de Granger e Huang (que permite a utilização de dados em painel). Contrariamente à maioria da literatura do tema, esta pesquisa não identificou a causalidade partindo da variável financeira para o produto. Em geral os resultados apontaram causalidade unidirecional, partindo do PIB agropecuário para o crédito rural.

Silva e Alves Filho (2008) investigaram os impactos econômicos do Pronaf em territórios de baixa dinamização econômica. Concluíram que o sistema de crédito à agricultura familiar vem apresentando impactos positivos nas variáveis macroeconômicas dos municípios analisados (território rural do médio Jequitinhonha).

\footnotetext{
${ }^{9}$ A equalização das taxas de juros é a diferença entre a taxa de juros de mercado e a taxa de juros aplicada no mercado de crédito rural. Aparentemente, isso parece um custo. Todavia, essa pesquisa verifica um relevante impacto positivo na produção rural, além de um aumento na receita fiscal. A atividade rural é incompatível com taxas de juros de mercado. A equalização das taxas de juros torna o financiamento rural viável.
} 
Lima (2005) concluiu que os modelos baseados na teoria insumo-produto de Leontief, que têm se mostrado de grande relevância na análise de impactos sobre a economia, não têm sido utilizados para estudos referentes à política de crédito rural. Portanto, justifica-se o estudo do impacto econômico de política governamental voltada ao crédito rural.

Neves e Bittencourt (2006) realizaram uma pesquisa sobre a direção da causalidade entre desenvolvimento financeiro e crescimento econômico no Brasil. Utilizando teste de causalidade de Granger foi detectado que o desenvolvimento econômico causa o crescimento agropecuário ao nível de significância de 10\%. A referida pesquisa utilizou como proxy para o desenvolvimento financeiro a relação crédito/PIB e M2/PIB.

Medeiros (2003) pesquisou estratégias para redução da pobreza e desigualdades e argumenta que a formação de uma moderna agricultura de alimentos, voltada para o mercado interno, é de grande relevância para um crescimento econômico mais equilibrado e homogêneo do ponto de vista setorial e regional, e, para a expansão dos salários reais, deu-se simultaneamente um processo concentrador. A redução dos preços dos produtos agrícolas nos anos 90, a desregulamentação do setor e a redução do crédito à agricultura ampliaram a marginalização dos produtores rurais desarticulados das grandes cadeias de comercialização.

\section{MODELO ECONOMÉTRICO}

A condição de estacionariedade é um pressuposto necessário e fundamental para a análise de séries temporais. Por exemplo, as condições válidas para o método de Mínimos Quadrados Ordinários (MQO) apenas vigoram na presença de séries temporais estacionárias. (ENDERS, 1995) Em assim sendo, um teste de raiz unitária foi aplicado para verificar a estacionariedade das séries de dados utilizadas no modelo. As referidas variáveis são: as séries de crédito, PIB agropecuário, a taxa de juros doméstica (Selic) e o INPC. Caso a série possua raiz unitária, ela então não é considerada estacionária. Portanto, para testar a hipótese nula de existência de uma raiz unitária, será utilizado o teste de Dickey-Fuller Ampliado (ADF).

O teste de causalidade de Granger deve ser utilizado para se detectar a dimensão preditiva de uma variável em relação à outra. Além disso, o teste de causalidade de Granger é importante no sentido de identificar a ordenação das variáveis no modelo VAR. O teste assume que o futuro não pode causar o passado nem o presente. (ENGLE; GRANGER, 1987; NELSON; PLOSSER, 1982) A ordenação das variáveis é importante no momento da construção do modelo VAR e no respectivo Teste de Impulso Resposta. 
Na análise da relação de causalidade entre as variáveis é necessário escolher o número apropriado de defasagens a ser utilizado no teste de Granger. De acordo com Davidson e Mackinnon (1993), a escolha de um número elevado de defasagens seria preferível, uma vez que, dessa forma, o analista pode verificar como a exclusão de algumas defasagens afeta o resultado das estimações.

A estatística do Critério de Akaike (AIC) indica as defasagens e a especificações do teste. Tem-se que especificar ainda se o teste possui intercepto e tendência. Em assim sendo, calculam-se essas estatísticas para cada série de dados, para se identificar o número de defasagens adequado a cada série.

Basicamente um VAR é um sistema de equações lineares onde cada variável é uma função dessa variável defasada de vários períodos e das defasagens das outras variáveis do sistema. Uma importante consideração a ser tomada é saber se devemos especificar o VAR utilizando as variáveis em níveis ou utilizar as variáveis em primeira diferença.

A especificação a ser utilizada depende crucialmente das propriedades das séries temporais. Ao se detectar variáveis não estacionárias e não cointegradas sugere-se a utilização do modelo VAR em primeira diferença. Ramaswamy e Slok (1998) apresentaram vários casos do uso do VAR irrestrito em comparação ao VAR restrito. O objetivo da metodologia VAR não é obter estimativas de parâmetros do modelo e sim acessar as inter-relações entre as variáveis do mesmo Ibrahim (2005).

\section{FUNDAMENTOS ECONOMÉTRICOS DO MODELO VAR}

Quando não estamos seguros da natureza exógena das variáveis em um sistema de equações, ou seja, se alguma variável é exógena com relação às demais em um conjunto de $n$ variáveis, então é proposto um modelo na qual cada variável do sistema seja afetada por todas as demais. Desta forma, qualquer variável é afetada pelas suas realizações correntes e passadas, bem como das realizações correntes e passadas das demais. Esta situação é descrita como modelo VAR estruturado ou primitivo, com $m$ defasagens, o qual permite capturar efeitos contemporâneos (feedback) e defasados entre o conjunto de variáveis.

Entretanto, os efeitos de feedback são caracterizados como componentes determinísticos, o que impede a solução do modelo estruturado. Além disso, esse sistema não se conceitua no formato reduzido para suas equações (ENDERS, 1995), a qual pode ser obtida por meio de manipulação algébrica, obtendo um VAR na forma padrão ou VAR irrestrito, que assume o seguinte formato: 


$$
\vec{x}_{t}=A_{0}+\sum_{i=1}^{m}\left(A_{i} \vec{x}_{t-i}\right)+\vec{\zeta}_{t}
$$

Onde $m$ representa o número de defasagens das variáveis, $\vec{x}_{t}$ é um vetor coluna $(n \times 1)$ de variáveis endógenas, assumido ser constituído por $n$ variáveis estacionárias, $\vec{x}_{t-i}$ é o vetor $\vec{x}_{t}$ com $i$ defasagens, $i=1,2,3 \ldots m$; Ao é um vetor coluna $(n \times 1)$ de constantes, representando os interceptos das equações do modelo, Ai vetores coluna $(n \times 1)$ de coeficientes de impactos do vetor $\vec{x}_{t-1}$. A variável $\vec{\zeta}_{t}$ é um vetor $(n \times 1)$ composto pelos termos de erros de previsão de cada variável do sistema. Estes termos de erros possuem média zero, variância constante e são individualmente não correlacionados, contudo podem apresentar correlação entre si.

O modelo VAR irrestrito, especificado na equação (1), encontra-se associado ao modelo VAR estruturado que possui o seguinte formato:

$$
B \vec{x}_{t}=B_{0}+\sum_{i=1}^{m}\left(B_{i} \times \vec{x}_{t-1}\right)+\vec{\varepsilon}_{t}
$$

Nessa modelagem o vetor de variáveis dependentes $\vec{x}_{t}$ é assumido ser constituído por variáveis estacionárias; os componentes do vetor $\overrightarrow{\boldsymbol{\varepsilon}}_{t}$ caracteriza as respectivas perturbações estocásticas em cada variável do sistema que, por hipótese, seguem um ruído branco. A matriz de coeficientes $B_{i}$ com $i=1,2,3 \ldots m$ incorpora os efeitos passados das variáveis sobre elas mesmas e sobre as demais variáveis. Finalmente o modelo VAR estruturado, dado pela equação (2) incorpora efeitos de realimentação (feedback), os quais se referem aos impactos instantâneos sobre alguma variável devido às mudanças unitárias sobre as mesmas. (ENDERS, 1995)

Nos modelos VAR irrestritos (integrados por variáveis estacionárias), as tendências estocásticas são removidas por diferenciação, resultando em séries estacionárias. Contudo, a melhor forma de tratar as variáveis não 
estacionárias é encontrar as combinações lineares das variáveis integradas que são estacionárias, sendo assim denominada de variáveis cointegradas. (ENDERS, 1995) Contudo, dada que as séries utilizadas neste artigo foram todas consideradas estacionárias como se mostra a seguir, utiliza-se um modelo VAR irrestrito em nível. O modelo econométrico proposto utiliza variáveis relevantes aos dois principais canais de transmissão da política monetária: o canal do crédito e o canal da taxa de juros.

\section{RESULTADOS EMPÍRICOS - TESTES E CAUSALIDADE}

Os dados utilizados nesse artigo foram coletados do sitio do Instituto de Pesquisa Econômica Aplicada (Ipea), ${ }^{10}$ selecionando dados trimestrais do primeiro trimestre de 1995 ao primeiro trimestre de 2009. Nas séries com dados mensais utilizaram-se as médias trimestrais. Assim, as séries temporais utilizadas nos modelos econométricos são as seguintes (a partir da letra " $d$ ", na ordem de milhões):

a. PIB Real Agropecuário (PIBReal), dessazonalizado, média 1995 $=100$;

b. Taxa de juros, Over-Selic (Selic);

c. INPC - Alimentos e bebidas (INPC);

d. Operações de crédito dos setores público e privado para setor rural, (CredRu_PIB);

e. Operações de crédito dos setores público e privado - agricultura. (CredAgri_PIB)

f. Operações de crédito dos setores público e privado para setor rural - comercialização. (CredCom_PIB)

g. Operações de crédito dos setores público e privado para setor rural - custeio. (CredCust_PIB)

h. Operações de crédito dos setores público e privado para setor rural - investimento,. (Credlnv_PIB)

i. Operações de crédito dos setores público e privado para setor rural - pecuária. (CredPec_PIB)

\footnotetext{
${ }^{10}$ Ver em: Instituto de Pesquisa Econômica Aplicada (2006).
} 
As estatísticas descritivas dessas variáveis são apresentadas na Tabela 1.

Tabela 1 - Dados estatísticos das séries temporais

\begin{tabular}{c|c|c|c|c|c}
\hline Variáveis & Média & Mediana & Máximo & Mínimo & Desvio padrão \\
\hline PIBReal & 130,20 & 129,12 & 169,74 & 92,96 & 22,57 \\
\hline Selic & 1,65 & 1,45 & 4,18 & 0,85 & 0,70 \\
\hline INPC & 0,53 & 0,46 & 4,61 & $-1,13$ & 0,91 \\
\hline CredRu_PIB & 0,06 & 0,06 & 0,36 & $-0,25$ & 0,10 \\
\hline CredAgri_PIB & 0,04 & 0,04 & 0,28 & $-0,22$ & 0,09 \\
\hline CredCom_PIB & 0,004 & 0,007 & 0,13 & $-0,12$ & 0,04 \\
\hline CredCust_PIB & 0,026 & 0,024 & 0,30 & $-0,18$ & 0,07 \\
\hline Credlnv_PIB & 0,03 & 0,03 & 0,13 & $-0,08$ & 0,03 \\
\hline CredPec_PIB & 0,016 & 0,017 & 0,083 & $-0,047$ & 0,01 \\
\hline
\end{tabular}

Fonte: Elaborada pelos autores.

O PIB agropecuário, ou PIB total real, apresentou um crescimento acelerado ao longo do período analisado. Todavia, obteve várias quedas pontuais ao longo do período. A Selic, por sua vez, apresentou uma queda acentuada ao longo do período analisado e mostrou alguns períodos de acentuada elevação como em 1998 e 1999. O INPC apresentou elevada oscilação em relação à sua média, sendo o ano de 2003 o período que apresentou a maior oscilação.

O crédito rural em relação ao PIB agropecuário apresentou muita oscilação com repetidas quedas e altas seguidas ao longo do período estudado. As outras modalidades de crédito estudadas apresentaram diversos graus de oscilações ao longo do período estudado, porém, aparentemente, essas oscilações se mostraram em torno da média do período.

Com relação às variáveis de crédito rural, a metodologia de cálculo do Bacen é de computar os saldos devedores das operações de crédito rural ao longo do tempo. Esta metodologia é acumulativa das operações de concessão de crédito rural, interferindo de forma relevante nos valores que se precisa para essa pesquisa. Portanto, para solucionar tal problema, calculam-se as diferenças trimestrais dos referidos saldos devedores de empréstimos rurais, no sentido de computar os valores novos contratados por trimestre nesta modalidade de empréstimo. Desta forma, obtêm-se os percentuais dos referidos empréstimos rurais nas modalidades mencionadas em relação ao PIB do setor agropecuário sem duplicidade. $\mathrm{O}$ volume de empréstimos foi calculado utilizando a seguinte fórmula: $E_{t+1}=E t+1-E$, onde ${ }^{E_{t+1}}$ é o volume de empréstimo contratado, ${ }^{t+1} E^{E} t$ é o valor de empréstimos contratados e acumulados até 
o período ${ }^{t}, \mathrm{e}^{E} t+1$ é o valor de empréstimos contratados e acumulados até ${ }^{t+1}$. Com essa metodologia calcula-se o volume de novos contratos de empréstimos a cada período.

Para se testar a estacionariedade destas variáveis empregou-se o teste de Dickey-Fuller. De acordo com os resultados descritos na Tabela 2, pode-se concluir que todas as variáveis se apresentam estacionárias em nível para o nível de significância de $1 \%$.

Tabela 2 - Teste de estacionariedade Dickey-Fuller Ampliado

\begin{tabular}{c|c|c|c|c}
\hline Série & Estacionariedade & Valores Críticos T & Estatística ADF & Significância \\
\hline PIBReal & Nível & $-4,1305$ & $-5,6269$ & $1 \%$ \\
\hline Selic & Nível & -3.5574 & $-3,6258$ & $1 \%$ \\
\hline INPC & Nível & -3.5526 & $-6,0779$ & $1 \%$ \\
\hline CredRu_PIB & Nível & $-3,5526$ & $-7,1175$ & $1 \%$ \\
\hline CredAgri_PIB & Nível & $-3,5526$ & $-6,7642$ & $1 \%$ \\
\hline CredCust_PIB & Nível & $-2,6101$ & $-2,9170$ & $1 \%$ \\
\hline CredCom_PIB & Nível & $-2,6069$ & $-5,5297$ & $1 \%$ \\
\hline Credlnv_PIB & Nível & $-2,6069$ & $-4,4395$ & $1 \%$ \\
\hline CredPec_PIB & Nível & $-3,5526$ & $-8,6001$ & $1 \%$ \\
\hline
\end{tabular}

Fonte: Elaborada pelos autores.

Em seguida, realizou-se o teste de Causalidade de Granger no sentido de verificar a direção e a intensidade da causalidade entre as referidas variáveis. O teste de Causalidade de Granger detecta a relação de causalidade de curto prazo entre as variáveis.

O teste de Causalidade de Granger foi realizado com um lag como resultado do critério de Schwarz. A Tabela 3 apresenta os resultados desse teste.

Tabela 3 - Teste de causalidade de Granger

\begin{tabular}{c|c|c|c|c}
\hline Variável & Causalidade & Variável & Valor-p do Teste F & Comentário \\
\hline Selic & & PIBReal & 0,1845 & Fraca relação \\
\hline INPC & & PIBReal & 0,6990 & Sem efeito \\
\hline CredCom_PIB & & PIBReal & 0,0777 & Forte relação \\
\hline CredCust_PIB & PIBReal & 0,0229 & Forte relação \\
\hline CredInv_PIB & PIBReal & 0,2431 & Fraca relação \\
\hline CredAgri_PIB & PIBReal & 0,0729 & Forte relação \\
\hline CredPec_PIB & PIBReal & 0,3175 & Sem efeito \\
\hline CredRu_PIB & PIBReal & 0,0429 & Forte relação \\
\hline PIBReal & Selic & 0,0088 & Forte relação \\
\hline
\end{tabular}




\begin{tabular}{c|c|c|c|c}
\hline PIBReal & INPC & 0,7440 & Sem efeito \\
\hline PIBReal & & CredCom_PIB & 0,0266 & Forte relação \\
\hline PIBReal & & CredCust_PIB & 0,0153 & Forte relação \\
\hline PIBReal & Credlnv_PIB & 0,1740 & Fraca relação \\
\hline PIBReal & CredAgri_PIB & 0,3923 & Sem efeito \\
\hline PIBReal & & CredPec_PIB & 0,4267 & Sem efeito \\
\hline PIBReal & CredRu_PIB & 0,0317 & Forte relação \\
\hline
\end{tabular}

Fonte: Elaborada pelos autores.

As variáveis de crédito para comercialização, crédito para custeio, crédito para agricultura e crédito rural total apresentaram significativa relação de curto prazo no PIB real do setor agropecuário. A Selic e o crédito para investimento apresentaram insignificante relação de curto prazo com o PIB real do referido setor. Já o INPC e o crédito para a pecuária não apresentaram efeito no PIB real agropecuário.

Com relação ao CredCom PIB e o PIB real agropecuário, detectou-se uma significativa relação bidirecional. O crédito rural na modalidade comercialização sugere exercer impacto no PIB real agropecuário. Esta modalidade de crédito age como medida de proteção das commodities agropecuárias às suas oscilações de preços. O crédito direcionado para comercialização parece ser um subsídio ao produtor rural, no sentido dele obter um preço mais justo.

O CredCust PIB apresentou uma significativa relação bidirecional com o PIB real do setor agropecuário. O crédito destinado ao custeio da produção parece exercer influência de curto prazo na produção agropecuária. Da mesma forma que o crédito dirigido para a comercialização, o crédito para custeio sugere ter um papel de apoio para que o produtor rural possa financiar o início da cadeia produtiva agropecuária.

Já o CredInv_PIB apresentou uma insignificante relação bidirecional com o PIBReal agropecuário no curto prazo. Ou seja, o PIB real impacta de forma discreta no volume de crédito rural para investimento em relação ao PIB rural e vice-versa. O crédito destinado ao investimento não parece exercer influência relevante no curto prazo. Nesse caso, era de se esperar que esta modalidade de crédito apresentasse influência relevante no PIB real da agropecuária, no sentido de incrementar a produtividade e ganhos de escala da produção rural no médio e longo prazo.

Não foi encontrada relação de causalidade de curto prazo entre INPC e a Selic e vice-versa. O INPC como proxy do índice de inflação dos pro- 
dutos agropecuários parece não sofrer influência direta da Selic, pois esta é direcionada ao combate inflacionário no agregado e não específico da agropecuária. Por outro lado, o INPC de bebidas e alimentos não influi no patamar da Selic por representar apenas um setor específico da economia, e só ele não justificaria uma alteração na taxa básica.

Detectou-se também uma significativa relação de causalidade unidirecional entre CredAgri_PIB e PIBReal agropecuário. O crédito destinado à agricultura parece impactar de forma relevante a produção agropecuária no curto prazo. Já o crédito destinado à pecuária em relação ao PIB real agropecuário parece não ter impacto de curto prazo no PIB real do setor rural e vice-versa.

Finalmente detectou-se uma significativa relação de causalidade bidirecional entre Credru_PIB e PIBReal agropecuário no curto prazo. Em termos agregados existe um impacto nos dois sentidos entre estas variáveis.

A seguir, encontram-se na Tabela 4 as especificações dos modelos VAR sugeridos e seus respectivos resultados dos testes de estabilidade.

Tabela 4 - Especificações e estabilidade dos modelos VAR

\begin{tabular}{c|c|c|c}
\hline Modelo & Especificação & Lags & Teste de estabilidade \\
\hline 1 & CredRu_PIB, Selic, INPC, PIBReal & 1 & Raízes: $0.9424,0.7450,0.1605,0.0030$ \\
\hline 2 & CredAgri_PIB, Selic, INPC, PIBReal & 1 & Raízes: $0.9425,0.7444,0.1702,0.0457$ \\
\hline 3 & CredCom_PIB, Selic, INPC, PIBreal & 1 & Raízes: $0.9441,0.6892,0.2268,0.2268$ \\
\hline 4 & CredCust_PIB, Selic, INPC, PIBreal & 1 & Raízes: $0.9407,0.7173,0.1951,0.0245$ \\
\hline 5 & Credlnv_PIB, Selic, INPC, PIBreal & 1 & Raízes: $0.9439,0.7508,0.1068,0.1068$ \\
\hline 6 & CredPec_PIB, Selic, INPC, PIBreal & 1 & Raízes: $0.9452,0.7460,0.1400,0.1337$ \\
\hline
\end{tabular}

Fonte: Elaborada pelos autores.

Os resultados apontam modelos VAR de 1 lag segundo o critério de Schwarz. Utilizou-se o teste lag structure que analisa as raízes do polinômio característico de cada modelo. Os resultados foram satisfatórios para todos os modelos sugeridos, ou seja, a especificação sugerida na modelagem VAR possui estabilidade, pois nenhuma raiz característica se colocou fora do círculo unitário do referido teste.

\section{FUNÇÃO DE IMPULSO RESPOSTA E DECOMPOSIÇÃO DE VARIÂNCIA DE CHOLESKY}

A Função de Impulso Resposta foi utilizada para se aferir os impactos dos choques nas diferentes modalidades de crédito rural no PIB real agropecuário. Considera-se que cada choque seja de um desvio padrão 
da série de crédito em questão no período de estudo. Na Tabela 5 são apresentados os referidos resultados.

Tabela 5 - Choques das Variáveis de Crédito no PIB real Agropecuário

\begin{tabular}{c|c|c|c|c}
\hline Modelo & Variável Crédito & Choque \% & Impacto Curto Prazo PIB\% & $\begin{array}{c}\text { Impacto EstávelPIB\% (24 } \\
\text { períodos) }\end{array}$ \\
\hline 1 & CredRu_PIB & $+10,35$ & $+0,54$ & $+0,01$ \\
\hline 2 & CredCom_PIB & $+4,23$ & $+1,89$ & $+0,54$ \\
\hline 3 & CredCust_PIB & $+7,64$ & $-1,90$ & $-0,12$ \\
\hline 4 & CredInv_PIB & $+3,53$ & $-0,65$ & $-0,21$ \\
\hline 5 & CredAgri_PIB & $+1,90$ & $+0,79$ & $+0,17$ \\
\hline 6 & CredPec_PIB & $+1,90$ & $-1,77$ & $-0,76$ \\
\hline
\end{tabular}

Fonte: Elaborada pelos autores.

Os resultados apontam as variáveis de crédito direcionadas à comercialização e à agricultura, em relação ao PIB real agropecuário como as linhas de crédito que obtiveram os melhores resultados no PIB real agropecuário. A linha de crédito rural que agrega todas as linhas de crédito analisadas também gerou impacto positivo relevante no PIB real agropecuário. Ou seja, um choque de $+10,35 \%$ no montante de crédito rural em relação ao PIB real agropecuário irá impactar no PIB real do setor rural no curto prazo em $+0,54 \%$ e, após 24 períodos, o efeito do choque é anulado.

As demais linhas de crédito direcionadas para investimento, custeio e pecuária induziram uma queda no PIB real agropecuário. No tocante à linha direcionada para investimento, sugere ter a finalidade de incrementar a infraestrutura, renovação de plantéis pecuários, dentre outras finalidades. Os resultados apontam uma queda do PIB real agropecuário pelo incremento de um maior volume nessa linha de crédito, provocando um impacto no PIB real agropecuário de $-0,65 \%$ amortecido para $-0,21 \%$ após 24 períodos.

A linha de crédito para o custeio é destinada a financiar a produção agropecuária, sobretudo no início da cadeia produtiva. O resultado parece sugerir que esta linha de crédito não tem o efeito desejado, que é induzir uma maior produção agropecuária. Em resumo, pode-se afirmar que um choque de $+7,64$ no montante de crédito ao custeio em relação ao PIB real agropecuário irá ter um impacto de $-1,90 \%$ no curto prazo e, após 24 períodos, $-0,12 \%$ no PIB real agropecuário.

O crédito destinado à agricultura parece impactar de forma positiva $O$ PIB real da agropecuária brasileira, fomentando a produção agrícola que também é à base de insumos para a produção pecuária. Em resumo, pode- 
-se aferir que, dado um choque de $+1,9 \%$ no volume de crédito destinado à agricultura em relação ao PIB real agropecuário, haverá um impacto no mesmo PIB real do setor rural em $+0,79 \%$ no curto prazo.

Os resultados também sugerem que estimular a linha de crédito à pecuária induz a uma queda significativa no PIB real do setor agropecuário. Possivelmente, o design equivocado de contratos de empréstimos pode ocasionar tal distorção. Pode-se afirmar que um choque de $+1,9 \%$ na disponibilidade de crédito destinado à pecuária em relação ao PIB real agropecuário irá afetar o mesmo PIB real do setor rural em -1,77\% no curto prazo.

Com relação à linha de crédito destinada à comercialização da produção agropecuária, verificou-se um impacto relevante dessa linha de crédito no PIB real do setor tanto no curto prazo como após 24 períodos. Ou seja, um choque de $+4,23 \%$ no crédito para comercialização irá impactar o PIB real agropecuário em +1,89\% no curto prazo e após 24 meses em $+0,54 \%$. Essa linha de crédito permite que a produção agropecuária seja negociada por preços justos de mercado, de certa forma imunizando o produtor agropecuário das grandes oscilações nos preços das commodities do setor. Portanto, pelo resultado obtido verificou-se que essa linha de crédito influi de forma decisiva para um impacto positivo na produção agropecuária.

Dado o racionamento de crédito ao setor rural abordado anteriormente, o maior impulso no PIB real da agropecuária deve ser atingido via crédito à comercialização na agricultura.

Na Tabela 6 são encontrados os resultados da Decomposição de Variância de Cholesky das variáveis de crédito em relação ao PIB real agropecuário no curto e longo prazo:

Tabela 6 - Decomposição de Variância de Cholesky das variáveis de crédito em relação ao PIB real agropecuário

\begin{tabular}{c|c|c}
\hline Variável de Crédito & Curto Prazo $-2^{\circ}$ Trimestre & Longo Prazo $-24^{\circ}$ Trimestre \\
\hline CredRu_PIB & $1,71 \%$ & $0,39 \%$ \\
\hline CredCom_PIB & $5,45 \%$ & $4,67 \%$ \\
\hline CredCust_PIB & $5,50 \%$ & $1,10 \%$ \\
\hline Credlnv_PIB & $0,59 \%$ & $0,61 \%$ \\
\hline CredAgri_PIB & $1,29 \%$ & $0,66 \%$ \\
\hline CredPec_PIB & $4,38 \%$ & $7,36 \%$ \\
\hline
\end{tabular}

Fonte: Elaborada pelos autores. 
Pelos resultados, pode-se verificar que as variáveis Credru_PIB, Credcust_PIB, Credcom_PIB e Credagri_PIB possuem impacto no PIB real agropecuário decrescente ao longo do tempo. Já as variáveis Credinv_PIB e Credpec_PIB apresentam impacto crescente no PIB real do setor agropecuário. A variável de crédito total rural em relação ao PIB real do setor evidencia que, de forma conjunta, as variáveis de crédito destinadas ao setor agropecuário apresentam impacto maior no curto prazo e, mesmo assim, de valor diminuto.

Na Tabela 7 são apresentadas as taxas de crescimento das séries de crédito ao setor agropecuário, ao longo do período analisado. Utilizou-se o critério da média aritmética ${ }^{11}$ no cálculo da taxa média de crescimento do crédito rural.

Tabela 7 - Taxas de crescimento médio do crédito rural

\begin{tabular}{c|c}
\hline Série de Crédito & Taxa \% ao trimestre (a.t.) médio \\
\hline CredRu_PIB & $-1,54$ \\
\hline CredCom_PIB & $-1,74$ \\
\hline CredCust_PIB & $-1,59$ \\
\hline CredInv_PIB & $-1,24$ \\
\hline CredAgri_PIB & $-1,59$ \\
\hline CredPec_PIB & $-1,00$ \\
\hline
\end{tabular}

Fonte: Elaborada pelos autores.

Verificou-se pelos resultados que todas as linhas de crédito rural sofreram redução de volumes de contratações em relação ao PIB real do setor agropecuário, durante o período de 1995T1 a 2008T4. A despeito da queda do crédito rural, em relação ao PIB real do setor agropecuário, este índice cresceu no mesmo período a uma taxa média de 1,32\%a.t.

Os resultados mostram que o impacto das variáveis de crédito no PIB real rural é de pequena monta, em comparação com dados agregados do crédito e PIB nacional. Todavia, a variável de crédito destinada à comercialização da produção rural, em relação ao PIB real agropecuário, apresentou uma resposta significativa, mesmo no longo prazo, conforme a FIR e a DVC.

Os dados de crédito são restritos aos contratados pelos bancos privados e oficiais. Todavia, o setor rural tende a encontrar outras formas de financiar a produção agropecuária, que não estão computadas nessa pesquisa. A

\footnotetext{
${ }_{11}$ Utiliza-se a seguinte fórmula: $\mathrm{Vn}=\mathrm{V} 0(1+\mathrm{in})$, onde $\mathrm{Vn}$ é o valor no período $\mathrm{n}$; $\mathrm{V} 0$ é o valor inicial; i é a taxa de crescimento pela média aritmética; e n o número de períodos. Essa metodologia é aplicada quando os dados apresentam comportamento linear.
} 
maior parcela de contratações partia dos bancos públicos, mas Gasques e Conceição (1999) detectaram uma redução drástica na participação destas instituições de crédito públicas, fato que deve contribuir para a redução no volume de contratações de empréstimos para o setor agropecuário verificado acima.

\section{CONCLUSÕES}

Os resultados encontrados demonstram que existe uma relação de causalidade bidirecional entre o crédito rural total como proporção do PIB real agropecuário e o PIB real do setor agropecuário. Quando o crédito rural total é injetado no setor primário da economia, a produção agropecuária tende a crescer, aumentando o PIB real do setor. Confirmam-se desta forma as conclusões de Conceição e colaboradores (1998).

Verifica-se, também, que a relação de causalidade depende de qual componente de crédito rural está sendo analisada. Detectou-se que os componentes de créditos destinados à comercialização e ao custeio como proporção do PIB real agropecuário apresentaram relação de causalidade bidirecional com o PIB real da agropecuária.

Já a proporção do crédito destinado ao investimento apresentou causalidade reversa com o PIB real agropecuário. Confirmam-se assim as conclusões de Cavalcante (2008) para o Brasil e de Chakrabarty (2003) para a Î́ndia.

Além de apresentarem relações de causalidade entre elas, apenas as proporções de créditos rural destinados à comercialização, à agricultura e o crédito total impactaram positivamente o PIB real do setor rural.

Um choque de $+4,23 \%$ na proporção de crédito destinado à comercialização apresenta um impacto de $+1,89 \%$ no PIB real do setor. Já um choque de $+1,90 \%$ na proporção de crédito destinado à agricultura gera um impacto de $+0,79 \%$ no PIB real do setor agropecuário. Esses resultados corroboram os de Akram e outros autores (2008) para o Paquistão e os de Chaovanapoonphol, Battese e Chang (2005) para a Tailândia.

Por sua vez, um choque de $+10,35 \%$ na disponibilidade da proporção de crédito rural total gera um impacto de apenas $+0,54 \%$ no PIB real do setor agropecuário. As outras modalidades de crédito impactaram negativamente o PIB real da agropecuária. A série de crédito rural total agrega todas as linhas de crédito ao setor rural e o efeito combinado é muito reduzido no PIB real do setor, mesmo no curto prazo. Essas conclusões vão ao encontro das conclusões de Gasques e Conceição (1999). 
A taxa Selic parece influenciar a maioria das linhas de crédito rural analisadas, além de apresentar uma relação de causalidade bidirecional com o PIB real da agropecuária. Embora as taxas de empréstimos ao setor rural sejam em patamares inferiores ao praticado pelas instituições financeiras aos outros setores, a Selic age como parâmetro base para as demais taxas de juros da economia brasileira. Portanto, uma variação na Selic tenderá a interferir nas taxas praticadas pelas instituições financeiras nas modalidades de crédito ao setor rural. (CASTRO; TEIXEIRA, 2004)

Dentre as linhas de crédito ao setor rural, a destinada à comercialização da agricultura foi quem mais contribuiu para o aumento do PIB real da agropecuária. Neste sentido, sugere-se que políticas direcionadas para o setor rural sejam mais intensamente voltadas à comercialização da agricultura, como forma de obter um relevante impacto positivo no setor.

A despeito da queda, em termos reais, do crédito agropecuário em relação ao PIB real do setor (-1,54\%a.t.), o produto agregado real do setor primário tem crescido em média 1,32\%a.t., possivelmente confirmando as conclusões de Belik e Paulillo (2001), que constataram que o produtor rural tem procurado formas alternativas de financiar a produção agropecuária além do financiamento bancário. Finalmente, detectou-se que o crédito destinado ao setor rural, em geral, é indutor de uma maior produção agropecuária, e que as linhas de financiamento que não apresentaram impacto positivo no PIB real da agropecuária devem ser reavaliadas e aprimoradas com objetivos a promover o crescimento do setor rural.

\section{REFERÊNCIAS}

AKRAM, W. et al. Impact of Agriculture Credit on Growth and Poverty in Pakistan. European Journal of Scientific Research, v. 23, n. 2, p. 243-251, 2008. (Time Series Analysis Through Error Correction Model)

ASIA DEVELOPMENT BANK. Rural Credit Project in the Socialist Republic of Viet Nam. Hanoi: Performance Evaluation Report, 2005.

ASSUNÇÃO, J.; CHEIN, F. Condições de crédito no Brasil rural. Revista de Economia e Sociologia Rural, Brasília, DF, v. 45, n. 2, p. 367-407, 2007.

BACHA, C. J. C.; DANELON, L.; BEL FILHO, E. D. Evolução da Taxa de Juros Real do Crédito Rural no Brasil-Período de 1985 a 2003. Teoria e Evidência Econômica, Passo Fundo, v.14, n.26, 2005.

BELIK, W.; PAULILLO, L. F. Mudanças no Financiamento da Produção Agrícola Brasileira. In: LEITE, S. Políticas Públicas e Agricultura no Brasil. Porto Alegre: Editora UFRGS, 2001. p. 95 - 120. 
BONELLI, R. Impactos Econômicos e Sociais de Longo Prazo da Expansão Agropecuária no Brasil: Revolução Invisível e Inclusão Social. Brasília, DF: IPEA, 2001. (Texto para Discussão 838).

CASTRO, E. R.; TEIXEIRA, E. C. Retorno nas gastos com a equalização das taxas de juros do crédito rural na economia brasileira. Revista de Política Agrícola, Brasília, DF, ano13, n.3, p. 52-57, jul./ago./set, 2004.

CAVALCANTE, I. M. Crédito Rural e Produto Agropecuário Municipal: uma Análise de Causalidade. 2008. 73 f. Dissertação (Mestrado em Economia) Faculdade de Administração, Economia e Contabilidade, Universidade de São Paulo, São Paulo, 2008.

CHAOVANAPOONPHOL, Y.; BATTESE, G. E.; CHANG, H. S. The Impact of Rural Financial Services on the Technical Efficiency of Rice Farmers in the Upper North of Thailand. School of Economics, University of New England, Armidale, NSW, 2005.

CHAKRABORTY, L. S. Public expenditure and human development: an empirical investigation. Paper prepared for the Wider International Conference on Inequality, Poverty and Human Well-Being. Helsinki: 2003.

CONCEIÇÃO, J. C. P. R. et al. Relação entre PIB agrícola e crédito rural no Brasil: aplicação do teste de causalidade de Granger. Sober, Brasília, DF, v. 2, p.127,1998.

DAVIDSON, R.; MACKINNON, J. G. Estimation and Inference in Econometrics. Nova York: Oxford Economic Press,1993.

DICKEY, D. A.; BELL, W. R.; MILLER R. B. Unit Roots in Time Series Models: Tests and Implications. The American Statistician, v. 40, p.12-26, 1986.

BANCO DO BRASIL. Diretoria de agronegócios. Evolução histórica do crédito rural. Revista de Política Agrícola, Brasília, DF, ano 13, n. 4, p. 10-17, out./nov./dez., 2004.

ENDERS, W. Applied Econometrics Time Series. New York: John Wiley, 1995.

FIGUEIREDO, A. M.; CASTRO, E. R. Relação Crédito Rural do Pronaf e Valor Bruto da Produção nos Diferentes Estados Brasileiros. In: CONGRESSO DA SOCIEDADE BRASILEIRA DE ECONOMIA, ADMINISTRAÇÃO E SOCIOLOGIA RURAL, 45., 2007, Londrina. Anais... Londrina: UEL, 2007.

FRANCO, J. et al. O Impacto da Demanda Final do Setor Agropecuário Paranaense sobre a Produção, Renda, Importações nas Décadas de 80 e 90. In: CONGRESSO DA SOCIEDADE BRASILEIRA DE ECONOMIA, ADMINISTRAÇÃO E SOCIOLOGIA RURAL, 44., 2005, Ribeirão Preto. Anais... Ribeirão Preto: [s.n], 2005. 
GASQUES, J. G.; CONCEIÇÃO, J. C. P. R. Financiamento da Agricultura: Dificuldades para Mobilizar Recursos. Brasília, DF: IPEA, 1999. (Boletim Conjuntural n. 46)

GUJARATI, D. N. Econometria Básica. 3. ed. São Paulo: Makron Books, 2004. INSTITUTO DE PESQUISA ECONÔMICA APLICADA. 2006. Disponível em: < http://www.ipeadata.gov.br/>. Acesso em: 25 mar. 2014.

LIMA, R. A. S. Avaliação da Política de Crédito Rural e a Teoria InsumoProduto: Um Artigo-Resenha. Teoria e Evidência Econômica, Passo Fundo, v. 13, n. 24, p. 125-138, 2005.

MATOS, M. A. Impactos da Crise Norte-Americana no Agronegócio Brasileiro. Brasília, DF: Organização das Cooperativas Brasileiras, 2008. (Informativo Técnico n. 25)

MEDEIROS, C. A. de. Desenvolvimento econômico e estratégias de redução da pobreza e das desigualdades no Brasil. Ensaios FEE, Porto Alegre, v. 24, n. 2, p. 323-350, 2003.

NELSON, C.; PLOSSER, C. Trends and Random Walks in Macroeconomic Time Series: Some Evidence and Implications, Journal of Monetary Economics, 10130-62, New York, 1982.

NEVES, A. L.; BITTENCOURT, M. V. L. Macroeconômicas, Políticas Setoriais e direção da Causalidade entre Desenvolvimento Financeiro e Crescimento Econômico no Brasil. In: CONGRESSO DA SOCIEDADE BRASILEIRA DE ECONOMIA, ADMINISTRAÇÃO E SOCIOLOGIA RURAL, 45., 2006, Fortaleza. Anais... Fortaleza: [s.n], 2006.

NUNES, E. P. CONTINI, E. E. Complexo Agroindustrial Brasileiro:

Caracterização e Dimensionamento. Brasília, DF: Associação Brasileira de Agribusiness, 2001.

PEREIRA, S. E.; FIGUEIREDO, A. S.; LOUREIRO, P. R. A. Avaliação do Impacto da Utilização de Crédito, da Educação e da Escolha do Canal de Comercialização na Horticultura: Caso do Núcleo Rural do Distrito Federal. RER, Rio de Janeiro, v. 44, n. 4, p. 773-799, 2006.

RAMASWAMY, R.; SLOK, T. The Real Effects of Monetary Policy in the European Union: What are the differences?. IMF Staff Papers, v. 45, p. 96-374, 1998.

SANTANNA, A.; FERREIRA, F. Crédito Rural: da especulação à produção. In: TORRES FILHO, E.; PUGA, F.; FERREIRA, F. (Org.). Visão do Desenvolvimento. Rio de Janeiro: BNDES, 2006. 
SILVA, S. P.; ALVES FILHO, E. Análise dos Impactos Econômicos do PRONAF em Territórios de Baixa Dinamização Econômica. 2008. Dissertação (Mestrado em Economia Aplicada) - Departamento de Economia, Universidade Federal de Viçosa, Viçosa, MG, 2008.

SPOLADOR, H. F. S. Reflexões Sobre a Experiência Brasileira de Financiamento da Agricultura. 2001. 93 f. Dissertação (Mestrado em Economia Aplicada) - Escola Superior de Agricultura Luiz de Queiroz, Universidade de São Paulo, Piracicaba, 2001.

XAVIER, L. F.; COSTA, J. M.; COSTA, E. F. Inadimplência ao Crédito Rural na Fruticultura Irrigada do Pólo Petrolina-Juazeiro. Revista Desenbahia, Salvador, n. 9, p. 35, set. 2008. 
